\title{
Monitoring blood pressure at home: guidance for Canadian patients
}

\author{
Ivona Mostarac RN MPH, Jim Thomas BSc MBA, Clare Atzema MD MSc
}

Cite as: CMAJ 2021 July 12;193:E1045. doi: 10.1503/cmaj.210268

Infographic available at: https://www.cmaj.ca/lookup/doi/10.1503/cmaj.210268/tab-related-content

1 p

Purchase a home blood pressure monitor approved by Hypertension Canada, preferably one used on the upper arm Most home blood pressure monitors sold commercially (> 85\% worldwide) do not measure blood pressure accurately. ${ }^{1}$ Hypertension Canada has a list of recommended devices that have been tested, are known to give valid readings and can be recognized in stores by their Recommended by Hypertension Canada logo (https://hypertension.ca/bpdevices).,1,2

2 Measure blood pressure twice in the morning and twice in the evening for 7 consecutive days (28 readings total) For people with an existing diagnosis of hypertension and stable blood pressure averages, home monitoring can be completed using the 7-day approach every 3 months. ${ }^{3}$ People with no history of hypertension can monitor their blood pressure yearly. ${ }^{4}$

\section{3}

\section{Home blood pressure readings that average to}

\section{$\geq 135 / 85 \mathrm{~mm} \mathrm{Hg}$ are considered high}

Elevated blood pressure readings in an otherwise asymptomatic person are rarely an emergency. ${ }^{4}$ Almost all (97\%) people who visit an emergency department after an elevated reading from a home or pharmacy monitor are discharged after being evaluated. ${ }^{5}$ Elevated readings warrant a timely appointment with a primary care provider. ${ }^{4}$ However, patients with elevated readings who are experiencing symptoms of a heart attack or stroke should seek immediate medical assessment. ${ }^{4}$

4.

Lifestyle modification may lower hypertension

Consistent systolic measurements of $135-139 \mathrm{~mm} \mathrm{Hg}$ or diastolic readings of $85-89 \mathrm{~mm} \mathrm{Hg}$ can be managed with a range of lifestyle changes, including a healthy diet and physical activity for 30-60 minutes daily. ${ }^{4}$

5

Medication(s) are likely needed for systolic readings $\geq 160 \mathrm{~mm} \mathrm{Hg}$ or diastolic readings $\geq 100 \mathrm{~mm} \mathrm{Hg}$ If high blood pressure is left untreated for months or years, the longterm risk of having a stroke or heart attack increases substantially. ${ }^{3,4}$ Fortunately, reducing high blood pressure with medications prescribed by a primary care provider, combined with home monitoring and lifestyle changes, greatly lowers these risks.,4

\section{References}

1. Padwal R, Berg A, Gelfer M, et al. The hypertension Canada blood pressure device recommendation listing: empowering use of clinically validated devices in Canada. J Clin Hypertens (Greenwich) 2020;22:933-6.

2. Blood pressure devices. Markham (ON): Hypertension Canada; 2020. Available: https://hypertension.ca/bpdevices (accessed 2020 Feb. 1).

3. Rabi DM, McBrien KA, Sapir-Pichhadze R, et al. Hypertension Canada's 2020 comprehensive guidelines for the prevention, diagnosis, risk assessment and treatment of hypertension in adults and children. Can J Cardiol 2020;36:596-624.

4. Understanding and managing your blood pressure. Markham (ON): Hypertension Canada; 2017. Available: https://www.hypertension .ca/images/2017_EducationalResources/HTC_UnderstandingBP_ ENG_PREVIEW.pdf (accessed 2020 Feb. 1).

5. Atzema CL, Wong A, Masood A, et al. The characteristics and outcomes of patients who make an emergency department visit for hypertension after use of a home or pharmacy blood pressure device. Ann Emerg Med 2018;72:534-43.

Competing interests: Clare Atzema reports grants from the Canadian Institutes of Health Research and the Sunnybrook Foundation, and salary support from the Heart and Stroke Foundation of Ontario and the Sunnybrook Research Institute, during the conduct of the study. No other competing interests were declared.

This article has been peer reviewed.

Affiliations: Sunnybrook Research Institute (Mostarac, Atzema), Toronto, Ont.; patient coauthor (Thomas), Oakville, Ont.; ICES Central and Department of Medicine (Atzema), Division of Emergency Medicine, Sunnybrook Health Sciences Centre, Toronto, Ont.

Content licence: This is an Open Access article distributed in accordance with the terms of the Creative Commons Attribution (CC BY-NC-ND 4.0) licence, which permits use, distribution and reproduction in any medium, provided that the original publication is properly cited, the use is noncommercial (i.e., research or educational use), and no modifications or adaptations are made. See: https://creativecommons.org/licenses/by-nc-nd/4.0/

Correspondence to: Ivona Mostarac, ivona.mostarac@sri.utoronto.ca 